\title{
Otoimmün hepatit tanılı hastada azatioprin tedavisi sonrası gelişen Kaposi sarkomu
}

\author{
Kaposi sarcoma development after azathioprine use in a patient with autoimmune hepatitis: A case \\ report
}

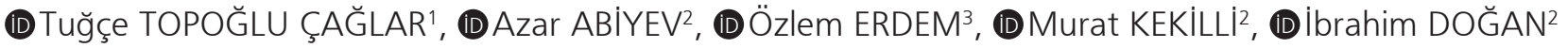 \\ Gazi Üniversitesi Tıp Fakültesi, 'İç Hastalıkları Anabilim Dalı, ${ }^{2}$ Gastroenteroloji Bilim Dalı, ${ }^{3}$ Patoloji Anabilim Dalı, Ankara
}

\begin{abstract}
Kaposi sarkomu, insan herpes virüsü-8 ile ilişkili mezenkimal bir neoplazmdır. Genellikle birincil veya ikincil immün yetmezliği olan hastalarda bulunur. Azatioprin gibi immünomodülatör ilaçlar otoimmün hepatit hastalığında etkilidir, ancak bunların kullanımı toksisite endişeleri nedeniyle sınırlıdır. Burada, otoimmün hepatit hastalığı için azatioprin tedavisi alan ve sonrasında Kaposi sarkomu gelişen, insan immün yetmezlik virüsü negatif bir olguyu sunuyoruz.
\end{abstract}

Anahtar kelimeler: Otoimmün hepatit, azatioprin, Kaposi sarkomu
Kaposi sarcoma is a mesenchymal neoplasm associated with human herpes virus-8. It is usually found in patients who have primary or secondary immune deficiency. Immunomodulatory drugs such as azathioprine are effective in the treatment of autoimmune hepatitis. However, their use is limited due to toxicity concerns. We present an human immmunodeficiency virus-negative case who received azathioprine treatment for autoimmune hepatitis and subsequently developed Kaposi sarcoma.

Key words: Autoimmun hepatitis, azathioprine, Kaposi sarcoma

\section{GíRiş}

Otoimmün hepatit (OIH) otoantikor pozitifliği ve yüksek gamaglobülin seviyeleri ile karakterize kronik otoimmün bir karaciğer hastalığıdır. OïH, klinikte asemptomatik olarak karaciğer fonksiyon enzimlerinde yükseklik ile görülebileceği gibi akut hepatit ile ortaya çıkıp kronik karaciğer hastalığı ve siroza kadar ilerleyebilir (1).

OiH tedavisinde azatioprin (AZA) hem remisyon indüksiyonunda hem de idame tedavide steroidle birlikte veya monoterapi olarak kullanılabilir. AZA kullanımına bağlı bulantı, kusma gibi hafif yan etkiler görülebileceği gibi, pansitopeni, hepatotoksisite, akut pankreatit, hematolojik maligniteler, progresif multifokal lökoensefalopati gibi ciddi komplikasyonlar da oluşabilmektedir (2). AZA kullanan hastalarda nadiren Kaposi sarkomu (KS) geliştiği bildirilmiştir (3-5).

Bu yazıda, otoimmün hepatitli bir hastada azatioprin kullanımı sonrasında gelişen Kaposi sarkomu olgusundan bahsedeceğiz.

\section{OLGU SUNUMU}

Yetmiş yaşında erkek hasta 14 ay önce halsizlik, yorgunluk ve bulantı şikayetleri ile hastaneye başvurdu. Yapılan

rutin tetkiklerinde karaciğer enzimlerinde yükseklik [alanin aminotransferaz (ALT): $157 \mathrm{IU} / \mathrm{L}$, aspartat aminotransferaz (AST): $95 \mathrm{IU} / \mathrm{L}$, alkalen fosfataz (ALP): $220 \mathrm{U} / \mathrm{L}$, gamma glutamil transferaz (GGT): $173 \mathrm{U} / \mathrm{L}$ ] saptandı. Ek kronik hastalığı ve alkol kullanımı olmayan hastanın hepatit belirteçleri, Epstein-Barr virüs (EBV), sitomegalovirüs (CMV), rubella, toksoplazma, Herpes Simplex virüs immünglobülin M (HSV IgM) negatifti. İmmünglobulin G (lgG): $20.9 \mathrm{~g} / \mathrm{l}$ (7.51-15.6), antinükleer antikorlar (ANA) pozitif, düz kas antikoru (ASMA) negatif, anti karaciğer-böbrek mikrozomal antikor (anti-LKM1) negatif, seruloplazmin $0.33 \mathrm{~g} / \mathrm{l}$ ( 0.2-0.60), bakır: $58.6 \mathrm{mcg} / \mathrm{gün}$ (0-60), alfa-1 antitripsin $1.64 \mathrm{~g} / \mathrm{l}$ (0.9-2) olarak sonuçlandı. Yapılan abdominal ultrasonografide (USG) karaciğer boyutu 150 mm olup, parankim yapısı granülerdi. Hastaya karaciğer biyopsisi yapıldı ve biyopsi sonucu otoimmün hepatit ve siroz (nekroinflamatuvar aktivite: 6-8, interfaz aktivite: 2-3, mgp ve IgG ile plazma hücrelerinde belirgin boyanma, fibrotik evre 3-4/6) ile uyumlu saptandı. Hastaya $0.5 \mathrm{mg} / \mathrm{kg} /$ gün prednizon başlandı, tedaviye yanıt alındığı için AZA 50 mg/gün eklendi. Prednizon 2 ay içinde azaltılarak kesildi ve AZA 100 mg/gün dozunda idame tedavisi olarak devam edildi. 
Son günlerde karın ağrısı, karında şişkinlik, nefes darlığı şikayetleri olan ve yeni gelişen şuur bulanıkığı olan hasta; spontan bakteriyel peritonit, hepatik ensefalopati ve hepatorenal sendrom ön tanıları ile kliniğimize yatııılı. Fizik muayenede sol aurikulada, bilateral el ve ayaklarda, bilateral bacaklarda mor renkli papül ve plaklar, batında grade 3 asit, oral mukozada ve sert damakta mor renkli papüller mevcuttu, bilateral bacaklarda pretibial ödem, akciğerlerde ince raller saptandı (Resim 1). Laboratuvar incelemelerinde hemoglobin ( $\mathrm{Hgb}): 7.5 \mathrm{~g} / \mathrm{dl}$, platelet: 38000, kan üre nitrojeni (BUN) $118 \mathrm{mg} / \mathrm{dl}$, kreatinin: $3.68 \mathrm{mg} / \mathrm{dl}$, sodyum: $127 \mathrm{mmol} / \mathrm{l}$, total bilirübin $2.2 \mathrm{mg} /$ $\mathrm{dl}$, direkt bilirübin $0.68 \mathrm{mg} / \mathrm{dl}, \mathrm{C}$ reaktif protein (CRP):
$141 \mathrm{mg} / \mathrm{l}$, prokalsitonin: $1.01 \mathrm{ng} / \mathrm{ml}$ olarak görüldü. Derin anemi ve trombositopeni nedeniyle AZA tedavisi kesildi. Hastanın günlük aldığı sıvı miktarı kısıtlandı, sefotaksim 3x2 gr/gün, laktuloz suspansiyon $3 \times 30 \mathrm{cc}$, terlipressin $4 \times 1 \mathrm{mg} / \mathrm{gün}$, albümin $1 \mathrm{~g} / \mathrm{kg}$ başlandı. Takiplerinde hastanın HES ve HRS kliniği düzeldi. Hasta cilt ve mukoza lezyonları açısından dermatolojiye danışıldı. Sol el dorsumundan alınan cilt biyopsisiyle [az sayıda hücrede insan herpes virüsü-8 (HHV-8) ile boyanma] hastaya Kaposi sarkomu tanısı kondu (Resim 2). Hastada insan immün yetmezlik virüsü (HIV) bakıldı ve negatif olarak sonuçlandı. Hastanın kendisinden bilgilendirilmiş onam formu alınmıştır.

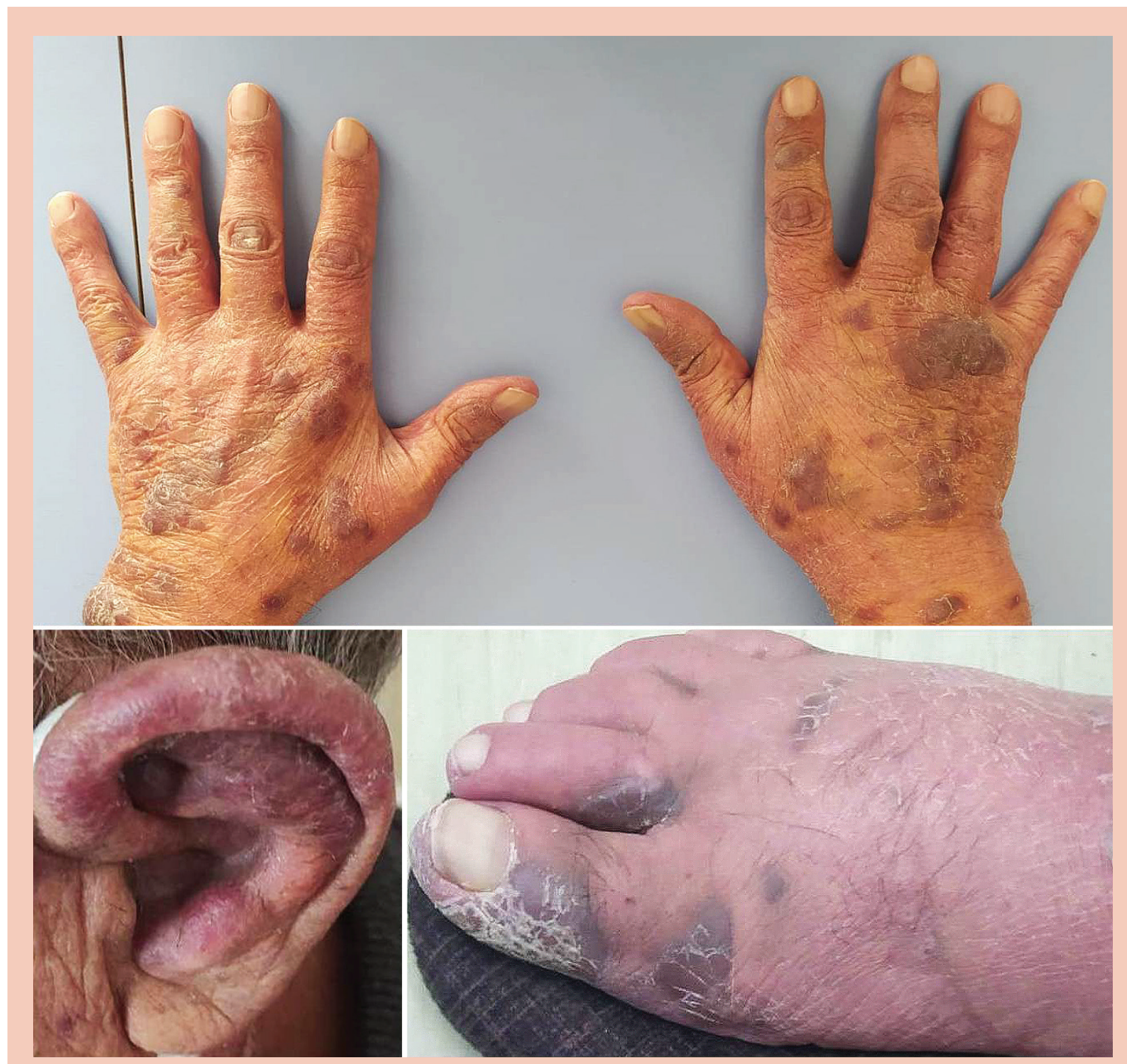

Resim 1. Kaposi sarkomu ekstremite ve aurikular tutulumu. 


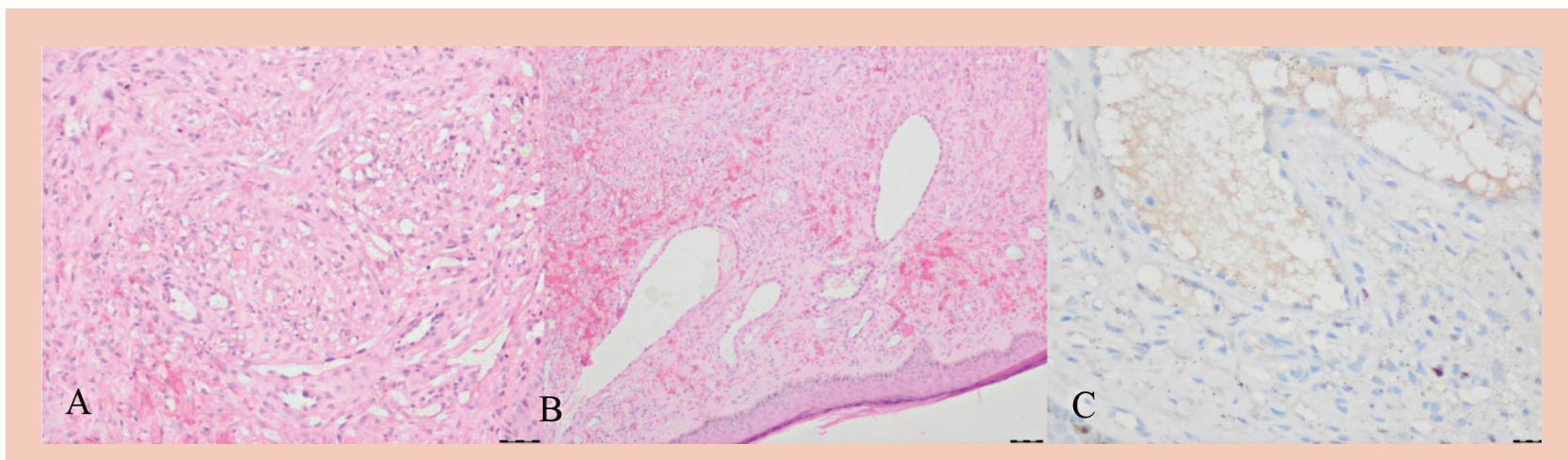

Resim 2. A, B: Kaposi sarkomu ile uyumlu cilt biyopsisinde dolgun iğsi hücrelerin yaprakları görülmektedir. C: İmmünhistokimyasal çalışmada HHV-8 ile az sayıda hücrede boyanma izlenmiştir.

\section{TARTIŞMA}

Kaposi sarkomu (KS) gelişimi için HHV-8 enfeksiyonu gerektiren bir anjiyoproliferatif hastalıktır. KS'nin klinik ve epidemiyolojik özelliklerine göre dört tipi tanımlanmıştır: klasik, endemik (Afrika tipi), kazanılmış bağışıklık yetersizliği sendromu (AIDS) ile ilişkili ve iyatrojenik (6). Klasik KS daha çok 60 yaş üstü bireylerde görülür. Bu tipte lezyonlar daha çok livedo-kahverengi yamalar şeklinde olup öncelikle ayaklardan başlar ve zaman içinde el ve kollar daha sık olmak üzere vücudun diğer bölgelerine, oral ve genital mukozaya yayılabilir. AIDS ile ilişkili KS tipik olarak HIV ile enfekte kişilerde görülen formdur ve klasik KS'den daha yaygın yerleşimli olması ve lezyonların hızlı ilerlemesiyle ayrılır. Ayrıca bu tipte lenf nodları, gastrointestinal kanal ve akciğer tutulumu da sık görülür. Endemik KS Orta Afrika'da özellikle gençler ve çocuklarda görülen KS tipidir (6).

Iyatrojenik KS daha çok başka bir hastalık nedeniyle (malignite, otoimmün hastalık, transplantasyon) kortikosteroid, azatioprin ve siklosporin gibi ajanlarla agresif immünsüpresif tedavi alan hastalarda ortaya çıkar (3-5). Illk iyatrojenik KS vakası 1969 yllında renal transplantlı immunsüprese bir hastada tanımlanmıştır (7). HHV-8 ile enfekte kişilerde immunsüpresif tedavi sonrası KS gelişme riski oldukça fazladır (8). Klinik görünüm klasik KS ile aynı olmakla birlikte lezyonların daha yaygın ve daha geniş, mukozal tutulumun daha sık olması beklenir. Literatürde immunsüpresif tedavi sonrası bildirilmiş malignite ve KS olguları vardır. Crohn hastalığı tedavisi için azatioprin ve steroid kullanan HIV negatif bir hastada 2 ay sonra KS geliştiği bildirilmiştir (4). Bizim hastamız otoimmün hepatit tedavisi için 14 ay boyunca 100 mg/gün AZA kullanmıştı, yaygın cilt ve mukozal tutulumları vardı ve evre $4 \mathrm{KS}$ olarak değerlendirildi.

Kaposi sarkomunun tedavi seçenekleri arasında cerrahi, lezyon içine kemoterapi, sistemik kemoterapi, interferon-alfa, kriyoterapi ve topikal terapi mevcuttur. Immunsüpresif tedavi sonrası gelişen Kaposi sarkomu olgularında tedavide ilk basamak immunsüpresif ajanın kesilmesidir (9). Bazı vakalarda immunsüpresif ajan kesilmesi sonrası lezyonlarda gerileme görülmüştür (10). Bizim vakamızda ajan kesilmesi sonrası gerileme görülmemiş ve öncelikli olarak radyoterapi başlanmışıır.

Sonuç olarak, bizim vakamızda olduğu gibi immünsüpresyonun, asemptomatik HHV-8 enfeksiyonundan KS gelişme riskini önemli ölçüde arttırdığı bilinmektedir. Bu yüzden immünsüpresif tedavi alan hastalarda cilt lezyonları açısından dikkatli olunmalı ve lezyon varlığında mutlaka ilgili bölüm tarafından değerlendirilmelidir.

Çıkar Çatışması: Yazarlar herhangi bir çıkar çatışması olmadığını beyan ederler. Ayrıca bu çalışmada herhangi bir kişi, kurum veya kuruluştan finansal destek alınmamıştır.

\section{KAYNAKLAR}

1. Mack CL, Adams D, Assis DN, et al. Diagnosis and Management of Autoimmune Hepatitis in Adults and Children: 2019 Practice Guidance and Guidelines From the American Association for the Study of Liver Diseases. Hepatology 2020;72:671-722.

2. Terziroli Beretta-Piccoli B, Mieli-Vergani G, Vergani D. Autoimmune hepatitis: Standard treatment and systematic review of alternative treatments. World J Gastroenterol 2017:23:6030-48.

3. Cetin B, Büyükberber S, Yilmaz IB, et al. Kaposi's sarcoma in patients with ulcerative colitis receiving immunosuppressive drugs: report of a case. Turk J Gastroenterol 2011;22:621-5.

4. Kilincalp S, Akıncı H, Hamamci M, Coşkun Y, Yüksel I. Kaposi's sarcoma developing in a HIV-negative Crohn's disease patient shortly after azathioprine and corticosteroid treatment. J Crohns Colitis 2014;8:558-9. 
5. Saxena A, Netchiporouk E, Al-Rajaibi R, Billick R, Roshdy O. latrogenic Kaposi's sarcoma after immunosuppressive treatment for granulomatosis with polyangiitis (Wegener's). JAAD Case Rep 2015;1:71-3.

6. Cesarman E, Damania B, Krown SE, et al. Kaposi sarcoma. Nat Rev Dis Primers 2019;5:9.

7. Siegel JH, Janis R, Alper JC, et al. Disseminated visceral Kaposi's sarcoma. Appearance after human renal homograft operation. JAMA 1969;207:1493-6.
8. Qunibi W, Al-Furayh O, Almeshari K, et al. Serologic association of human herpesvirus eight with posttransplant Kaposi's sarcoma in Saudi Arabia. Transplantation 1998;65:583-5.

9. Schneider JW, Dittmer DP. Diagnosis and Treatment of Kaposi Sarcoma. Am J Clin Dermatol 2017;18:529-39.

10. Trattner A, Hodak E, David M, Neeman A, Sandbank M. Kaposi's sarcoma with visceral involvement after intraarticular and epidural injections of corticosteroids. J Am Acad Dermatol 1993;29:890-4 